\section{La normalización de la política fiscal debe ser un objetivo económico y político el 2017.}

Por Carlos García* y Gabriel Ruiz ${ }^{* *}$

*Ph.D. en Economia, University of California (LA), EE.UU. Académico FEN UAH

"M.A. in Economics Ilades-Georgetown, Pacifico Macroeconomía y Finanzas.

La politica fiscal ha sido un pilar en la estabilización de la economia chilena en las últimas décadas. La estabilidad no solo ha sido económica, sino también política. Desde 1990, los gobiernos demodas sociales de los diferentes sectores de la población ya que han contado con recursos para implementar reformas y satisfacer las demandas sin desestabilizar la economia. Como explicaremos, no solo el Gobierno ha tenido recursos para apuntalar el crecimiento sino tambièn para apoyar a la economia cuando el escenario internacional ha sido desfavorable.

La exitosa estrategia fiscal se debe a que el presupuesto de cada tombargo, desce el 2009 le politica fiscal se ha Estructural. Sin trategia por buenas razones. Pero ya es tiempo de normalizar esta politica y convertirla en un objetivo económico y politico del 2017. Como explicaremos en esta columna, los beneficios de esta nopolitica fiscal discreciona

En pocas palabras, la regla de Balance Estructural consiste en fijar los gastos totales de manera tal de tener un balance estructural de un 0\% del PIB real (antiguamente del 1\%). La idea de fondo es mantener un nivel de gasto fiscal en linea con los ingresos estructurales de la economia chilena, resumidos en dos parämetros fundamentales: el crecimiento del PIB potencial y el precio de cobre en el largo plazo. Esto permite mantener un nivel de gasto relativamente independiente del ciclo economico, por ejemplo, sin dejar de invertir en gasto social, i.e., educación, salud y prevision, en caso que la economia deje de, ceer temporalmente. Por el contrario, si deconomia se expande, se acumulan ahorros fiscales para los anos

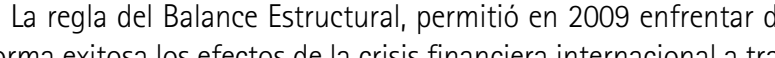
vés de una politica fiscal contra cíclica. En términos simples, una politica fiscal contra ciclica permite al Gobierno apoyar a la economía cuando crece menos o cae en una recesión. En esa ocasión los ahorros provinieron del boom en el precio de los commodities de años anteriores que permitió acumular enormes cantidades de reservas del sector minero. Sin embargo, esa exitosa política fisca 2009 fue a costa de dejar de lado la regla del balance estructura, situación que ha continuado hasta la actualidad. El experimento fiscal de ese año en manos del Ministro de Hacienda, Andrés Velasco ha sido -sin la menor duda- uno de los mejores ejemplos de una buena politica fiscal. Muy por el contrario, otros paises mayoritariaevaron a cabo politicas fiscales contractivas con

¿ia toderemos a la regla del Balance Estructural el 2017? En teoria todo es posible. Sin embargo, los buenos deseos se enfrentan (a) cimiento ecó́m tero ha languidecido transformándose y el crecrmeno mis permanente que transitorio ta unica holgura fiscal, asta el momento, es la reforma tributaria que si generá recur. Balance Estructural pero con un gasto fiscal más ajustado justo en una situación de desaceleración económica. Es decir contrariamente de lo ocurrido en 2009, para volver a la regla al equilibrio Gobierno deberia paradöjcamente hacer una politica pro ciclica: bajar el crecimiento del gasto, que para todos los efectos práctiás la ansiada recuperación económica. Por tanto, ta respuesta a la pregunta de este parrafo es negativa: tendremos que esperar algunos años más para volver en plenitud a la regla de

"Más en detalle, todo indica que aún estamos lejos de cumplir la meta" de Balance Estructural. Como hemos explicado, esta regla se los ingresos publicos se encuentren en su nivel de tendencia. Por el vas: un precio del cobre inferior a su promedio $y$ expectativa' crecimiento cada vez más a la baja (las cuales para este año son de $16 \%$ y a principios del año 2015 se encontraban en 3.5\%2. En consecuencia, como ya lo adelantó el Ministro de Hacienda, Rodrigo Valdés este año tendremos un importante déficic fisca.

Análogamente, para analizar y comprender el problema desde tra arista del presupuesto, es útil dividirlo en dos ítems: el llamado Aporte Fiscal Libre y los Programas especiales del tesoro público. En la Tabla 1 se detallan las variaciones de ambos componentes presupuestados para el año 2016. basa en que en el mediano plazo, las variables fundamentales para
El aporte fiscal libre es, sin duda alguna, el más conocido y pro-

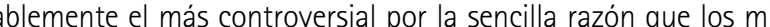
nisterios se encuentran dentro de este item. Al respecto, el reciente informe semestral publicado por la Dipres (29 de julio), (ver Tabla muestra a los principales ministerios con mayor gasto corriente yasto en capital aprobados con su respectiva ejecución en comparación con el mismo periodo del año anterior. Lo importante es que tanto el gasto corriente como el de capital no muestran bajas significativas como se esperaba, sino más bien, presentan una estabilidad considerable dada la coyuntura macroeconómica actua En efecto, después del 2009, el gasto fiscal ha aumentado constanesperando, deste Hacienda un défict fiscal sobre $\mathrm{PIB}$ para 25

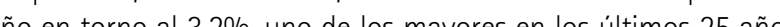
(Gráfico 1).

Por consiguiente, no habria que alarmase por un nuevo défici da especialmente para estos tiempos, es decir, debemos est parte alta del ciclo económico para compensar los déficits fiscales acumulados estos años. Sin embargo, el problema es si los años de crecimiento futuros serán suficientes para dar vuelta los actuales déficits fiscales, para asi lograr volver a un presupuesto estructura equilibrado y además acumular recursos suficientes para solventar gastos en futuras crisis. Como se observa el esfuerzo es doble, restaurar el equilibrio fiscal no basta, tambien se debe volver a ahorar cuantiosos recursos para asegurar la estabilidad económica y

Con todo, el déficit del próximo año debería estar por debajo de

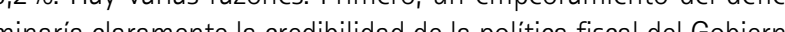
y podria ser que el riesgo pais aumentara y con ello se encarecería el financiamiento externo para la economía chilena. Segundo, se espera un crecimiento de la economía chilena. Al parecer hemos tocado fondo y en los próximos trimestres se consolidaría un crecimiento de manera tal, que volvamos a aumentar a tasas del 30 para mediados del 2017. Tercero, se espera también una recuperación del precio del cobre en torno a un 5\%. Todos estos elementos apuntan a que el ministerio de Hacienda podria al fin reducir e déficit fiscal y encaminarse definitivamente a retomar la regla de Balance Estructura.

Creemos, que moderando el gasto fiscal en un punto menos de crecimiento en 2017 respecto del 2016, más un crecimiento de sera seria una buena señal para los mercados y buen comienzo para En lefinitiva, sera

en el desempeño de la política fisca

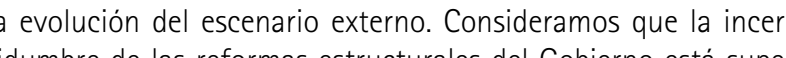
政 ha empeñado en hacer una política fiscal responsable y auster Tampoco el Banco Central de Chile está convencido de subir la tasa de política monetaria dado los últimos datos de la inflación crecimiento ${ }^{3}$. Por tanto, la incertidumbre sobre el futuro de enomia chilena está asentada en el comportamiento de los mercados internacionales. Al respecto, los bancos centrales de mundo siguen manteniendo la liquidez con tasas de interés reales negativas y con ello soportan el crecimiento de la Zona Euro y de

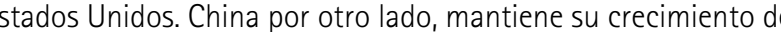
el precio del cobre en 2017. Todos estos elemencos indicarian que el proximo año será un año mas de recuperación para la economia mundial.

Recalcando, esperamos que la situación fiscal de Chile mejore sulancialmente 2017. Entonces, estarán dadas las condiciones para colize un esfuerzo econémico, sino también voluntad politica para que los diferentes sectores entiendan que a politic fiscel ha sido une te le democia chilena la restauracion palatina de la regla del Ba ance Estructural debe ser priorida para que esta politica continúe siendo la más valiosa herramienta de estabilización del ciclo económico que hemos tenido en los últimos 25 años.

\section{Total Aportes}

Aporte Fiscal Libre

Programas Especiales del Tesoro Público

Var. Anual

iente: Dipres, presupuesto año 2015 y 2016.$$
\text { Tabla 2: Anallisis del gasto corriente y de capita }
$$

Total Leyde Fiecución al

Total $\underset{\substack{\text { leyde } \\ \text { presupues } \\ 2010}}{2030}$ 32,881, 2011 2016
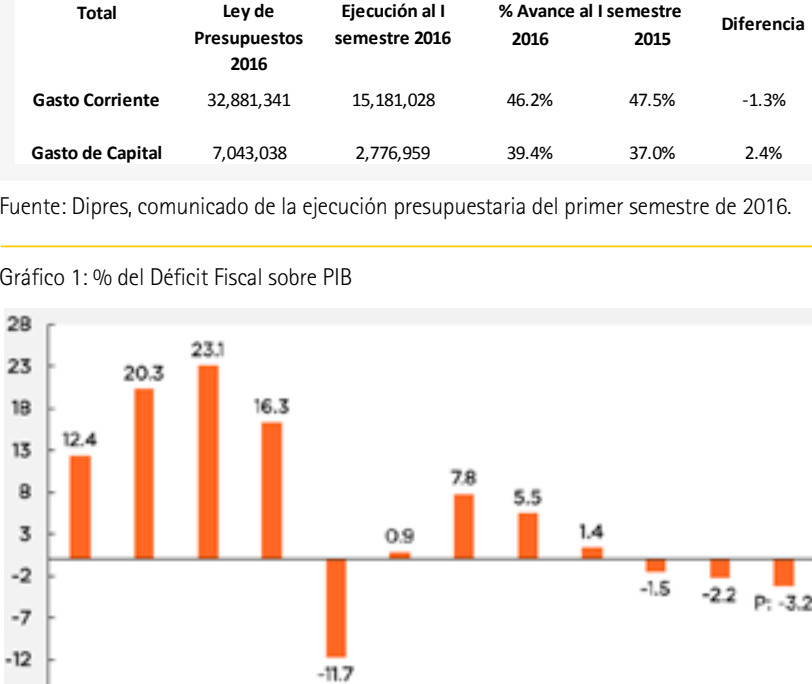

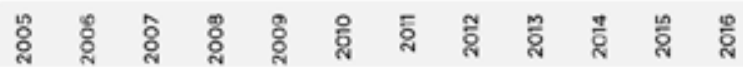
Fuente: Banco Central de Chile. El Iultimo dato corressonde a cifra indicada por el Ministro 'Encuesta de Expectativas Económicas de julio del Banco Central de Chile.
'Además, y no menos interesante, es saber las consecuencias de la baja del PII la base de los gastos pressupuestados

${ }^{3}$ Notar que, en las últimas 4 reuniones de politica monetaria, la única opción 